\title{
Health care utilization by preterm infants with respiratory complications in Quebec
}

\author{
Jennifer S Landry MD MSc ${ }^{1,2}$, Dan Croitoru ${ }^{1}$, Yulan Jin ${ }^{1}$, Kevin Schwartzman MD MPH ${ }^{1,2}$, \\ Andrea Benedetti $\mathrm{PhD}^{1,3}$, Dick Menzies MD MSc ${ }^{1,2}$
}

JS Landry, D Croitoru, Y Jin, K Schwartzman, A Benedetti, D Menzies. Health care utilization by preterm infants with respiratory complications in Quebec. Can Respir J 2012;19(4):255-260.

INTRODUCTION: Despite notable advances in prenatal and neonatal care, respiratory distress syndrome (RDS) and bronchopulmonary dysplasia (BPD) remain important complications of preterm births, and their longterm sequelae are poorly understood.

OBJECTIVE: To describe health care utilization and costs over a 16- to 25-year follow-up period in a cohort of preterm infants with respiratory complications.

METHODS: Using provincial health administrative databases from Quebec, a cohort of individuals who were born prematurely with complications of RDS and/or BPD between 1983 and 1992 were identified. From these databases, which cover all Quebec residents, health services use, medication prescriptions, associated diagnoses and costs were tabulated.

RESULTS: A total of 3442 subjects with respiratory complications following preterm birth were identified, of whom 773 had been diagnosed with BPD and 2669 had RDS without BPD. Asthma was diagnosed twice as frequently (1.7 to 2.4 times) in the BPD group compared with the RDS group, with more frequent hospital readmission, and outpatient and emergency room visits. Although respiratory causes remained the main reason for consultation in both groups, $3.7 \%$ and $3.4 \%$ of the outpatient visits were for mental or psychological ailments, such as depression, attention deficit hyperactivity disorder or dysthymia for the BPD and RDS groups, respectively.

CONCLUSION: BPD patients experienced more hospital admissions, outpatient and emergency rooms visits, and were more likely to suffer from respiratory illnesses and to use respiratory drugs than RDS patients. Neurological and psychiatric complications occurred at a high frequency in both RDS and BPD subjects, and were associated with significant use of antipsychotic and antidepressant medications.

Key Words: Bronchopulmonary dysplasia; Health care utilization; Preterm birth; Respiratory distress syndrome

$\mathrm{P}_{\mathrm{r}}^{\mathrm{rath}}$ eterm birth has been an under-recognized global health issue, partly because of a lack of data on the extent of the problem and its long-term consequences. In 2005, 13 million preterm babies were born worldwide. Africa (119 per 1000 births), North America (106 per 1000 births), and Asia (91 per 1000 births) have the highest rates of preterm birth (1). Preterm births also appear to be increasing in numbers. In Canada and the United States, the rate of preterm birth has increased by $35 \%$ in the past 25 years, mainly because of assisted reproduction (1). According to the 2009 White Paper Report of the March for Dimes Foundation (1), more than one million infants die each year because of prematurity, while those who survive have an increased risk of morbidities such as cerebral palsy, chronic lung disease, blindness and hearing loss. Even late preterm births (34 to 36 weeks' gestation) are associated with disabilities, jaundice and delayed brain development (1).

\section{L'utilisation des soins de santé par les prématurés qui présentaient des complications respiratoires à la naissance au Québec}

INTRODUCTION : Malgré les progrès remarquables des soins prénatals et néonatals, le syndrome de détresse respiratoire (SDR) et la dysplasie bronchopulmonaire (DBP) demeurent des complications importantes en cas de naissances prématurées, et on comprend mal leurs séquelles à long terme.

OBJECTIF : Décrire l'utilisation et les coûts des soins de santé pendant une période de suivi de 16 à 25 ans auprès d'une cohorte de nourrissons prématurés ayant eu des complications respiratoires.

MÉTHODOLOGIE : À l'aide de bases de données administratives de santé du Québec, les chercheurs ont repéré une cohorte de personnes nées prématurément qui avaient eu une complication sous forme de SDR ou de DBP entre 1983 et 1992. À partir de ces bases de données, qui couvrent tous les habitants du Québec, ils ont comptabilisé l'utilisation des services de santé, les prescriptions de médicaments, les diagnostics connexes et les coûts.

RÉSULTATS : Au total, les chercheurs ont repéré 3442 sujets ayant des complications respiratoires après une naissance prématurée, dont 773 avaient reçu un diagnostic de DBP et 2669 , un SDR sans DBP. L'asthme était deux fois plus diagnostiqué (1,7 à 2,4 fois) dans le groupe ayant eu une DBP que dans celui ayant eu un SDR. Ce premier groupe était réhospitalisés plus souvent et consultait davantage en soins ambulatoires ou à l'urgence. Même si, dans les deux groupes, les causes respiratoires demeuraient la principale raison des consultations, 3,7 \% et 3,4\% des visites ambulatoires portaient sur des troubles de santé mentale ou psychologique, tels que la dépression, le trouble de déficit de l'attention avec hyperactivité ou la dysthymie, dans les groupes ayant présenté une DBP et un SDR, respectivement.

CONCLUSION : Les patients ayant eu une DBP étaient hospitalisés plus souvent, consultaient davantage en soins ambulatoires et à l'urgence et étaient plus susceptibles de souffrir d'une maladie respiratoire ainsi que d'utiliser des médicaments contre ces troubles que les patients ayant eu un SDR. Les complications neurologiques et psychiatriques étaient très fréquentes, tant chez les sujets ayant eu un SDR qu'une DBP, et s'associaient à une utilisation importante d'antipsychotiques et d'antidépresseurs.

Despite notable advances in prenatal and neonatal care, respiratory distress syndrome (RDS) and bronchopulmonary dysplasia (BPD) remain important respiratory complications of preterm births, frequently resulting in mortality as well as short-term and long-term morbidities. The economic consequences of preterm birth have been studied in the first years of life; the adverse sequelae of preterm birth have considerable long-term consequences for health services and for society as a whole (2). Attendant costs increased with the degree of prematurity, along with the number of hospital readmissions and the mean length of stay for each readmission (2). No studies have investigated the long-term health care use of preterm infants into adulthood. The present study aimed to describe the health care cost and health care utilization over a 16- to 25-year period in a preterm cohort with respiratory complications (RDS and BPD) born between 1983 and 1992 in Quebec.

${ }^{1}$ Respiratory Epidemiology and Clinical Research Unit, McGill University; ${ }^{2}$ Respiratory Division, Department of Medicine, McGill University

Health Centre; ${ }^{3}$ Department of Epidemiology, Biostatistics $\&$ Occupational Health, McGill University, Montreal, Quebec

Correspondence: Dr Jennifer S Landry, McGill University Health Centre, 3650 Avenue Saint-Urbain, Room K1.18, Montreal,

Quebec H2X 2P4. Telephone 514-934-1934 ext 32152, fax 514-843-2083, e-mail jennifer.landry@mcgill.ca 


\section{METHODS}

\section{Study design and selection of subjects}

The present study was performed using a retrospective cohort of subjects with respiratory complications of premature birth born in Quebec between 1983 and 1992. This was accomplished using databases provided by the provincial health care system of Quebec, the Régie de l'assurance-maladie du Québec (RAMQ), which is the centralized health ministry responsible for insuring all residents in the province of Quebec and reimbursing the physicians, pharmacists and hospitals for care provided. These databases, described in detail below, ensured complete capture of the study population living in Quebec, because medical coverage is universal and free. The International Classification of Diseases, Ninth Revison (ICD-9) codes for diagnoses (3) have been used in these databases since April 1, 1981 (until March 31, 2006), and ICD-10 codes since April 1, 2006.

These databases were used to identify all subjects with a preterm birth, defined as a gestational age $<37$ weeks (using the ICD-9 code 765.*) and diagnoses of associated respiratory complications - either BPD (ICD-9 code 770.7) or RDS (ICD-9 code 769.*). This cohort was separated into two groups: infants who were diagnosed with BPD (with or without an antecedent diagnosis of RDS); and infants diagnosed with RDS but not BPD.

Data were extracted from January 1, 1983 (from April 1, 1987 in the case of the MED-ECHO database) to March 31, 2008, which represents a minimum of 16 years and a maximum of 25 years of follow-up data on all subjects still alive and residing in Quebec.

A subset of subjects from this retrospective cohort were matched to a previously described population of infants admitted to the Montreal Children's Hospital (Montreal, Quebec) between January 1, 1983 and December 31, 1992, following a preterm birth (4). The population included all infants with preterm birth, defined as gestational age $<37$ weeks (259 days) admitted with a diagnosis of BPD or RDS. This cohort was used to provide neonatal characteristics of the premature population not available in the provincial databases, such as birth weight, gestational age, severity of BPD (5) and Apgar score.

Access to the RAMQ database received the approval of the Commission d'accès à l'information du Québec and the present study was approved by a research ethics board of the McGill University Health Centre (Montreal, Quebec).

\section{Administrative databases}

Four provincial databases administered by RAMQ were used in the present study:

1. MED-ECHO database (6), which contains information on acute care hospitalizations and day surgeries performed in Quebec. Each record contains identifying demographic information along with the primary diagnosis on admission and 15 possible secondary diagnoses (7). This database was initiated April 1, 1987. This was used to obtain details on hospitalization, date of admission and length of stay, as well as details on the admission, principal and secondary diagnoses and the cause of death when applicable for all subjects born after April 1, 1987.

2. Medical services database, which includes data on medical billing (type of service performed, specialty of claimant, setting where the service was provided [outpatient clinic, private clinic, emergency room, in-patient]) as well as the number of claims and date on which the service was performed and the cost paid by the RAMQ to the billing physician. This database is complete from January 1, 1983.

3. A database containing information on all insured subjects, including their age, postal code, annual household income (based on the mean annual income of the forward sorting area, as defined by the first three digits of the postal code) as provided by Statistics Canada based on the most recent population census, their sex and their status (dead or alive) along with the date of the event, when applicable.
4. Prescription drug database, which included data on all drugs dispensed (date of service, drug identification number code, American Health Foundation class, dosage, duration), length of utilization and associated fees (service fees, contribution from the beneficiary and the amount covered by the RAMQ). This is complete for all children $<18$ years of age in Quebec since January 1, 1997. Data in the RAMQ prescription database have been validated and found to be accurate and reliable (8).

\section{Hospitalization and pharmaceutical costs}

The RAMQ and MED-ECHO databases do not provide any data on hospitalization costs. Therefore, estimates for the average cost of hospitalization in Quebec were used over the period from 1983 and 2008, using data from the Canadian Institute of Health Information and Health Canada $(9,10)$. Using the Case Mix Group (CMG+) methodology, it estimates a hospitalization cost of $\$ 839.17 /$ day $(9,10)$. For the pharmaceutical costs, the cost reflects the period starting from January 1, 1997, in which the mean age of the BPD cohort was 7.3 years and the RDS cohort was 5.8 years until March 31, 2008, and comprises $30.4 \%$ of BPD subjects and $28.6 \%$ of RDS subjects included in the study.

\section{Statistical analyses}

All preterm infants were grouped into two categories for all analyses: preterm with RDS and preterm with BPD (with or without preceding RDS).

Characteristics associated with RDS and BPD were examined by comparing each group using a univariate approach. One-way ANOVA or $t$ tests were used to compare means of continuous variables, and Mantel-Haenszel $\chi^{2}$ tests were used to compare ordinal variables. Tests based on the Poisson distribution were used for count and rate outcomes. $\mathrm{P} \leq 0.05$ was considered to be statistically significant.

For multivariable analysis, variables that were significantly associated with the outcome in univariate analyses were initially included. Variables were then selected using a stepwise forward method, with the cut-off for significance set at $\mathrm{P} \leq 0.05$ (11,12). A multivariate Poisson regression model (11) was used to determine the association of clinical factors with the number of admissions, outpatient and emergency room visits. Statistical analyses were conducted using SAS version 9.2 (SAS Institute Inc, USA).

\section{RESULTS}

\section{Baseline characteristics of the study population}

A total of 3442 subjects were identified from the provincial databases, of whom 773 were diagnosed with BPD following a preterm birth. Table 1 summarizes the main characteristics of the study population including the prevalence of commonly reported complications of prematurity and of other diagnoses made in the perinatal period. The lifetime incidences of cor pulmonale and asthma are also included.

The mean $( \pm$ SD) annual rate of preterm birth in Quebec was $62.6 \pm 3.3$ per 1000 live births between 1983 and $1992(13,14)$. The BPD and the RDS rates per 1000 live births were found to be 0.8 and 2.7, respectively, during the same period, and complicated $1.3 \%$ and $4.3 \%$, respectively, of all preterm births.

Twenty-four subjects with BPD died following their initial discharge from hospital (mean age at death 4.4 years), as did 38 subjects with RDS (mean age at death 4.1 years). The leading causes of death in those with BPD were cor pulmonale and chronic respiratory failure (17\%), other respiratory causes $(42 \%)$ and hydrocephalus or other congenital abnormalities of the central nervous system (13\%). The leading cause of death in the RDS group was obstructive hydrocephalus and other congenital abnormalities of the central nervous system.

\section{Hospital readmissions, outpatient department and emergency room} visits

The mean duration of the follow-up for preterm BPD and RDS subjects up to 2008 was 19.3 and 17.6 years, respectively. As shown in 
TABLE 1

Characteristics of study population

\begin{tabular}{|c|c|c|c|}
\hline & \multicolumn{2}{|c|}{ Subjects } & \multirow[b]{2}{*}{$\mathbf{P}$} \\
\hline & BPD & RDS & \\
\hline $\mathrm{n}$ & 773 & 2669 & - \\
\hline Male sex, n (\%) & $413(53.5)$ & $1641(61.5)$ & $<0.0001$ \\
\hline Age in 2008 , years & $19.3 \pm 2.8$ & $17.6 \pm 1.7$ & $<0.0001$ \\
\hline Mortality, n (\%) & $24(3.1)$ & $38(1.4)$ & 0.002 \\
\hline Age at death, years & $4.4 \pm 5.9$ & $4.1 \pm 6.1$ & 0.37 \\
\hline Household income, \$ & $\begin{array}{c}50,059.57 \pm \\
30,271.74\end{array}$ & $\begin{array}{c}49,987.49 \pm \\
27,839.96\end{array}$ & 0.56 \\
\hline \multicolumn{4}{|c|}{ Diagnoses present in the perinatal period, $\mathrm{n}(\%)$} \\
\hline Anoxic encephalopathy & $292(37.8)$ & $848(31.8)$ & 0.002 \\
\hline Hyperbilirubinemia & $243(31.4)$ & $1133(42.5)$ & $<0.0001$ \\
\hline Patent ductus arteriosus & $220(28.5)$ & $324(12.1)$ & $<0.0001$ \\
\hline Seizures & $91(11.8)$ & $140(5.3)$ & $<0.0001$ \\
\hline Retinopathy of prematurity & $82(10.6)$ & $34(1.3)$ & $<0.0001$ \\
\hline Intraventricular hemorrhage & $73(9.4)$ & $89(3.3)$ & 0.0002 \\
\hline Pulmonary interstitial emphysema & $71(9.2)$ & $197(7.4)$ & 0.09 \\
\hline Apnea of prematurity & $32(4.1)$ & $74(2.8)$ & 0.05 \\
\hline Necrotizing enterocolitis & $25(3.2)$ & $50(1.9)$ & 0.04 \\
\hline Aspiration & $21(2.7)$ & $49(1.8)$ & 0.74 \\
\hline Hydrocephalus & $10(1.3)$ & $12(0.5)$ & 0.002 \\
\hline \multicolumn{4}{|c|}{ Diagnoses present after the initial discharge } \\
\hline Asthma, n (\%) & $208(26.9)$ & $315(11.8)$ & $<0.0001$ \\
\hline $\begin{array}{l}\text { Cor pulmonale/pulmonary } \\
\text { hypertension, } \mathrm{n}(\%)\end{array}$ & $21(2.7)$ & $2(0.1)$ & 0.03 \\
\hline \multicolumn{4}{|c|}{ Perinatal characteristics of matched subjects } \\
\hline n (\% of total) & $241(31.2)$ & 409 (15.3) & - \\
\hline Birth weight, kg & $1.09 \pm 0.48$ & $2.24 \pm 0.68$ & $<0.0001$ \\
\hline Gestational age, days & $194.9 \pm 22.3$ & $237.7 \pm 21.5$ & $<0.0001$ \\
\hline Male sex, n (\%) & $143(59.3)$ & $266(65.0)$ & 0.15 \\
\hline 1 min Apgar score & $3.9 \pm 2.4$ & $6.5 \pm 2.4$ & $<0.0001$ \\
\hline 5 min Apgar score & $6.3 \pm 2.1$ & $7.98 \pm 1.9$ & $<0.0001$ \\
\hline
\end{tabular}

Data presented as mean $\pm S D$ unless otherwise indicated. BPD Bronchopulmonary dysplasia; RDS Respiratory distress syndrome

Table 2, BPD subjects were more likely to seek medical attention than RDS subjects over that period of time, either in the outpatient setting or the emergency department. BPD subjects were also hospitalized more frequently and for longer periods of time than their counterparts. The annual rate of hospitalizations was consistently greater in the BPD than in the RDS group at almost all ages as shown in Figure 1.

Asthma was diagnosed twice as frequently (1.7 to 2.4 times) in the BPD group compared with the RDS group, during hospital readmission, outpatient or emergency room visits. Although respiratory causes remained the main reason for consulting in both groups, $3.7 \%$ and $3.4 \%$ of the outpatient visits were for mental or psychological conditions, such as depression, attention-deficit hyperactivity disorder or dysthymia, for the BPD and RDS groups, respectively (Table 2).

The most frequent medical and surgical specialties consulted for all medical visits in the outpatient settings (which include outpatient departments and private offices) were pediatrics $(27.9 \%$ and $29.5 \%$ for BPD and RDS, respectively), otorhinolaryngology (5.7\% and 5.2\%), ophthalmology (5.7\% and 3.9\%), respirology $(5.5 \%$ and $0.6 \%)$ and psychiatry $(4.5 \%$ and $3.3 \%)$. Only the latter two were found to be statistically different between the two groups.

Table 3 summarizes the adjusted rate ratios for hospital readmissions, outpatient and emergency room visits. Male sex and a diagnosis of BPD were associated with more frequent hospital readmissions, outpatient and emergency room visits. A diagnosis of patent ductus arteriosus, seizures and asthma also significantly impacted all outcome measures, regardless of the presence of BPD and/or RDS. The length of
TABLE 2

Health care utilization: Number of hospitalizations, outpatient and emergency room visits, and rate of most frequent diagnoses

\begin{tabular}{|c|c|c|c|}
\hline & \multicolumn{2}{|c|}{ Subjects } & \multirow[b]{2}{*}{$\mathbf{P}$} \\
\hline & BPD & RDS & \\
\hline \multicolumn{4}{|l|}{ Hospitalizations following initial discharge } \\
\hline $\begin{array}{l}\text { Subjects with at least one hospitalization, } \\
\mathrm{n}(\%)\end{array}$ & $690(89.3)$ & $2653(99.4)$ & - \\
\hline Hospitalizations/subject, mean \pm SD & $5.0 \pm 7.3$ & $2.9 \pm 3.3$ & $<0.0001$ \\
\hline Hospitalizations/person-year & 1.6 & 1.3 & $<0.0001$ \\
\hline Length of stay, days, mean \pm SD & $14.9 \pm 47.3$ & $10.1 \pm 44.0$ & $<0.0001$ \\
\hline \multicolumn{4}{|c|}{$\begin{array}{l}\text { Principal diagnoses at hospital readmission* (discharge diagnoses) } \\
\text { per person-year }\end{array}$} \\
\hline $\begin{array}{l}\text { Acute respiratory tract infection and other } \\
\text { respiratory diagnoses }\end{array}$ & 1.08 & 0.09 & $<0.0001$ \\
\hline Asthma & 0.63 & 0.26 & $<0.0001$ \\
\hline \multicolumn{4}{|l|}{ Outpatient visits } \\
\hline Visits/subject, mean \pm SD & $108.3 \pm 74.8$ & $72.3 \pm 50.5$ & $<0.0001$ \\
\hline Visits/person-year & 7.4 & 5.7 & 0.006 \\
\hline \multicolumn{4}{|c|}{ Diagnoses made during outpatient visits per person-year } \\
\hline BPD and other chronic lung diseases & 15.11 & - & - \\
\hline Asthma & 11.13 & 4.55 & $<0.0001$ \\
\hline Unspecified nonpsychotic mental disorder & 1.86 & 1.66 & $\mathrm{~N} / \mathrm{S}$ \\
\hline Dysthymic disorders (depression, anxiety) & 1.59 & 1.35 & $\mathrm{~N} / \mathrm{S}$ \\
\hline Attention deficit hyperactivity disorder & 1.46 & 1.55 & $<0.05$ \\
\hline \multicolumn{4}{|l|}{ Emergency room visits } \\
\hline Visits/subject, mean $\pm \mathrm{SD}$ & $15.4 \pm 18.9$ & $12.0 \pm 14.5$ & 0.0002 \\
\hline Visits/person-year & 3.1 & 2.7 & 0.005 \\
\hline \multicolumn{4}{|c|}{$\begin{array}{l}\text { Principal diagnoses at emergency room visits }{ }^{\dagger} \text { (discharge diagnoses) } \\
\text { per person-year }\end{array}$} \\
\hline Asthma & 3.56 & 1.99 & $<0.0001$ \\
\hline $\begin{array}{l}\text { Acute respiratory tract infection and other } \\
\text { respiratory diagnoses }\end{array}$ & 1.00 & 0.79 & $<0.05$ \\
\hline
\end{tabular}

Data presented as mean number unless otherwise indicated. *Principal diagnosis at discharge from hospital; ${ }^{\dagger}$ Diagnosis at discharge from emergency room. BPD Bronchopulmonary dysplasia; N/S Not statistically significant; RDS Respiratory distress syndrome

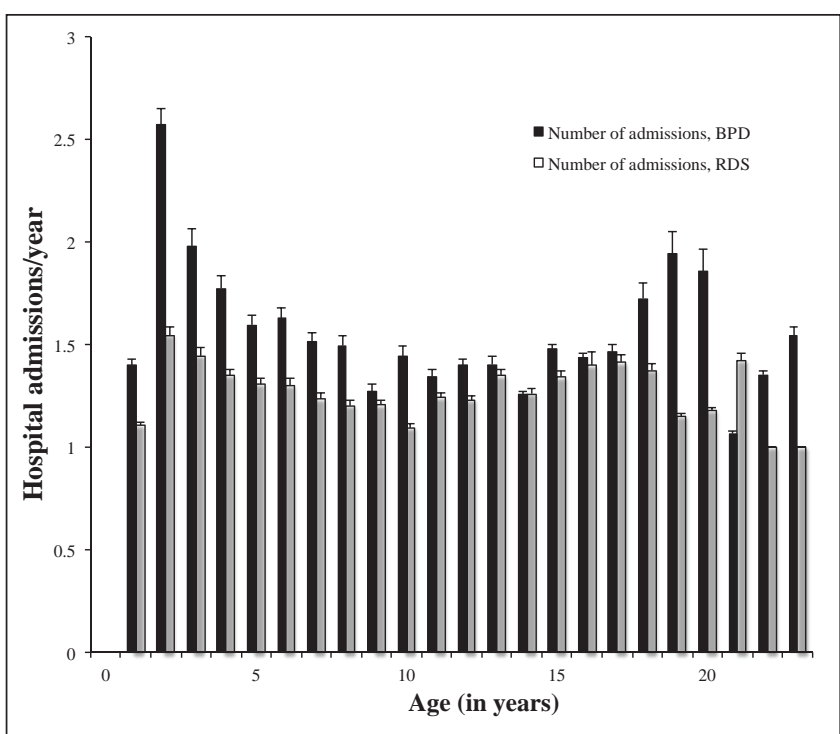

Figure 1) Annual rate of hospital readmissions according to age group following initial discharge from hospital. Error bars represent SD of the mean. BPD Bronchopulmonary dysplasia; RDS Respiratory distress syndrome 
TABLE 3

Adjusted rate ratios for the number of hospital readmissions, outpatient and emergency room visits

\begin{tabular}{|c|c|c|c|}
\hline & \multicolumn{3}{|c|}{ Adjusted rate ratio* $(95 \% \mathrm{Cl})$} \\
\hline & $\begin{array}{l}\text { Hospital } \\
\text { readmissions }\end{array}$ & $\begin{array}{l}\text { Outpatient } \\
\text { visits }\end{array}$ & $\begin{array}{l}\text { Emergency } \\
\text { room visits }\end{array}$ \\
\hline Male sex & $1.1(1.06-1.14)$ & $1.01(1.01-1.02)$ & 1.08 (1.05-1.1) \\
\hline $\begin{array}{l}\text { Annual household } \\
\text { income }<\$ 20,000^{\dagger}\end{array}$ & $0.92(0.86-0.99)$ & $0.71(0.70-0.73)$ & $0.83(0.8-0.86)$ \\
\hline \multicolumn{4}{|l|}{ Perinatal diagnoses } \\
\hline BPD & $1.44(1.37-1.5)$ & $1.25(1.23-1.26)$ & 1.08 (1.05-1.1) \\
\hline $\begin{array}{l}\text { Patent ductus } \\
\text { arteriosus }\end{array}$ & $1.11(1.05-1.16)$ & $1.17(1.16-1.18)$ & $1.07(1.04-1.1)$ \\
\hline $\begin{array}{l}\text { Anoxic } \\
\text { encephalopathy }\end{array}$ & 1.05 (1.01-1.09) & $1.02(1.01-1.02)$ & $0.97(0.95-0.99)$ \\
\hline Seizures & $2.18(2.04-2.33)$ & $1.34(1.32-1.37)$ & $1.54(1.48-1.61)$ \\
\hline \multicolumn{4}{|c|}{ Diagnosis made after the perinatal period } \\
\hline Asthma & $2.53(2.42-2.63)$ & $1.39(1.38-1.41)$ & $2.18(2.13-2.22)$ \\
\hline \multicolumn{4}{|c|}{ Perinatal characteristics $^{\ddagger}$} \\
\hline $\begin{array}{l}\text { Apgar score at } 1 \mathrm{~min}^{\S} \\
\text { (per point) }\end{array}$ & $1.12(1.08-1.16)$ & $1.06(1.05-1.07)$ & $1.00(0.97-1.02)$ \\
\hline $\begin{array}{l}\text { Maternal age }{ }^{\Uparrow}, \\
\text { per year }\end{array}$ & $0.98(0.97-1.00)$ & $1.00(1.00-1.01)$ & $1.01(1.00-1.02)$ \\
\hline $\begin{array}{l}\text { Birth weight**, } \\
\text { per } 100 \mathrm{~g}\end{array}$ & $1.04(1.02-1.07)$ & $1.04(1.03-1.04)$ & $1.03(1.01-1.04)$ \\
\hline $\begin{array}{l}\text { Gestational age }{ }^{\dagger \dagger}, \\
\text { per week }\end{array}$ & $1.07(1.03-1.11)$ & $1.06(1.05-1.07)$ & $1.08(1.05-1.11)$ \\
\hline Severity of BPD & $1.45(1.27-1.65)$ & $1.27(1.23-1.31)$ & $1.79(1.58-2.03)$ \\
\hline
\end{tabular}

*Also adjusted for the subjects' year of birth; ${ }^{+}$This cutoff was used according to the definition of low income used by Statistics Canada (13); ${ }^{\ddagger}$ Analyses performed using the 650 subjects matched between the Régie de l'assurance maladie du Québec databases and the Montreal Children's Hospital (Montreal, Quebec) cohort; ${ }^{\S}$ The rate ratio is for each point subtracted from the Apgar score at $1 \mathrm{~min}$; "The rate ratio is for each additional year of maternal age; ${ }^{*}$ The rate ratio is for each $100 \mathrm{~g}$ of lower birth weight; ${ }^{+\dagger}$ The rate ratio is for each week of lower gestational age; ${ }^{\ddagger \pm}$ The rate ratio is for more severe bronchopulmonary dysplasia (BPD) disease, from mild, moderate to severe as defined by the National Institutes of Health consensus definition (5)

stay of the hospital readmissions was associated with a diagnosis of $\mathrm{BPD}(\mathrm{P}=0.0047)$ and an age $<2$ years at readmission $(\mathrm{P}<0.0001)$ (data not shown). Annual household income $<\$ 20,000$ was found to be inversely proportional to the number of hospital admissions, outpatient and emergency room visits.

Cost of health care utilization by expreterm subjects with respiratory complications in Quebec

Table 4 summarizes the cost per person-year for medical services (billing fees to the physician) and hospitalization costs for BPD and RDS subjects between 1983 and March 31, 2008. An average of $\$ 13,472$ was spent per subject with BPD per year for medical consultation fees, hospitalizations and medications as shown in Table 4.

Medication use by cohort members

A total of 69 prescription drugs were dispensed per person-year in the BPD group compared with 39 in the RDS group $(P=0.002)$ for the 11 -year duration of the pharmaceutical follow-up. As summarized in Table 5, respiratory drugs, including corticosteroids, inhaled corticosteroids with or without long-acting beta-agonists (eg, Advair [GSK, Canada], Symbicort [AstraZeneca, Canada]) beta-agonist drugs (eg, salbutamol), anticholinergics (eg, ipratropium) and smoking cessation aids, were all used significantly more often in BPD than RDS patients as were skeletal muscle relaxants (commonly used for the treatment of
TABLE 4

Cost of health care utilization by preterm subjects with respiratory complications in Quebec between 1983 and 2008

\begin{tabular}{lccc}
\hline & BPD & RDS & P \\
\hline Medical services & & & \\
$\quad$ Total cost & $4,267,619$ & $7,856,764$ & - \\
$\quad$ Cost/person-year, mean \pm SD & $362 \pm 127$ & $222 \pm 65$ & $<0.0001$ \\
Hospitalization costs* & & & \\
Total cost & $49,253,405$ & $65,812,746$ & - \\
Cost/person-year, mean \pm SD & $12,935 \pm 11,643$ & $10,395 \pm 16,251$ & 0.12 \\
Pharmaceutical services ${ }^{\dagger}$ & & & \\
$\quad$ Total cost & 495,824 & 909,934 & - \\
$\quad$ Cost/person-year, mean \pm SD & $175 \pm 88$ & $101 \pm 23$ & 0.06 \\
$\begin{array}{l}\text { Total cost } \\
\quad \text { Total cost/person-year, } \\
\text { mean } \pm \text { SD }\end{array}$ & $13,472 \pm 527$ & $10,719 \pm 625$ & 0.02 \\
\hline
\end{tabular}

Values expressed in 2008 Canadian dollars. *The mean cost of hospitalization in Quebec over the period from 1983 and 2008 was estimated at \$839.17/day using data from the Canadian Institute of Health Information and Health Canada, using Case Mixed Group methodology $(21,22) ;{ }^{\dagger}$ Pharmaceutical data from 1997 onward. BPD Bronchopulmonary dysplasia; RDS Respiratory distress syndrome

muscle spasticity observed in cerebral palsy), anticonvulsants, antidepressants and antipsychotics and anxiolytics. Central nervous system stimulants, such as methylphenidate, used in the treatment of attention deficit hyperactivity disorders, were used frequently in both groups (31\% of BPD and $27 \%$ of RDS). The mean duration of each therapy, once prescribed, did not differ across the two groups.

\section{DISCUSSION}

In 2008, the mean age of the preterm BPD and RDS cohorts was 19.3 and 17.6 years, respectively, and the follow-up duration covered a period of 25 years. This provided a good representation of the long-term use of health care services of the study population. The prevalence of neonatal morbidities associated with preterm births, such as necrotizing enterocolitis, patent ductus arteriosus and intraventricular hemorrhage, was comparable with that cited in previous reports $(15,16)$.

Hospital readmissions following initial discharge, outpatient visits and emergency room visits were significantly more frequent in the cohort of BPD subjects, as were the medical and total cost per personyear for these BPD subjects. If we estimate that $1.3 \%$ of preterm infants born in Canada will develop BPD and $4.3 \%$ will develop RDS, this represents an annual cost of $\$ 5.1$ million for BPD subjects and $\$ 13.4$ million for RDS subjects until they reach adulthood. The role of home oxygen programs could not be examined in the present study but is likely to influence the health care use and costs by influencing hospital length of stays. A previous study reported that $26.1 \%$ of BPD subjects born during the study period required oxygen at discharge (17).

Asthma and respiratory complications occurred significantly more frequently in the BPD group and, interestingly, psychiatric illnesses (anxiety, depression, attention deficit hyperactivity disorder) composed a significant proportion of outpatient visits for both the BPD and RDS groups. Although data on health care use of healthy controls were not included in the present analysis, a study on the lifetime use of health care services by adolescents (18) revealed that 54 controls, (mean age 16.9 years) recruited between 2000 and 2003 and living in Quebec, typically had no contact with a psychiatrist on an annual basis and a lifetime contact rate of $7.4 \%$.

Respiratory drugs, such as anticholinergics, beta-agonists and inhaled corticosteroids, were used more frequently in the BPD subjects compared with RDS subjects, and were used on average more than three months per year for the 11-year duration of the pharmaceutical 


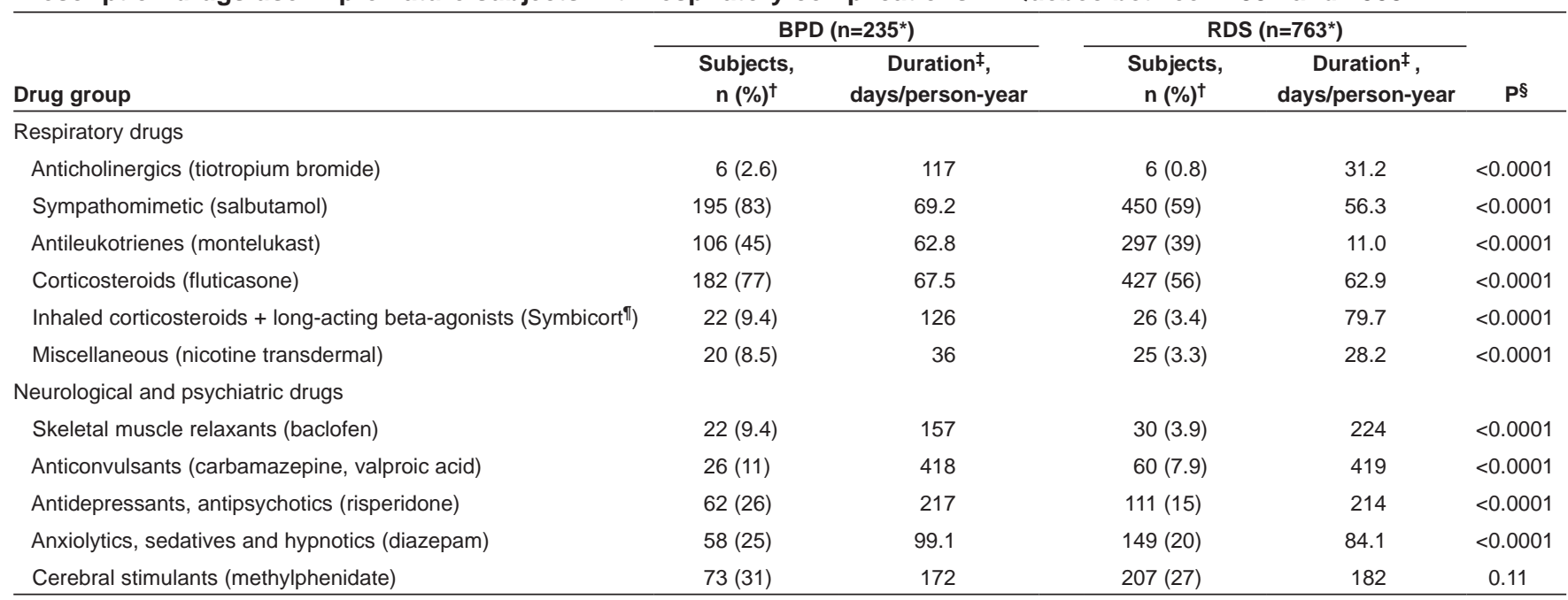

${ }^{*}$ Mean number of subjects included in the database over the 11 -year period; ${ }^{\dagger} D a t a$ presented as the total number of subjects who ever received the drug (percentage over the total number of subjects in the groups); ${ }^{\ddagger}$ Mean duration of therapy per person-year, values expressed in days and limited to subjects to whom the drug was dispensed; ${ }^{\$} P$ value associated with the differences observed between the numbers of prescriptions issued per person-year between the two groups (data not shown); "AstraZeneca Canada, Inc. BPD Bronchopulmonary dysplasia; RDS Respiratory distress syndrome

follow-up. This suggests that respiratory symptoms are persistent well into the late teenage years and early adulthood. This may impact the quality of life of BPD survivors because it is also associated with more frequent hospitalizations and emergency room visits, and an overall greater medication use.

Both groups used anticonvulsant, antidepressant and antipsychotics medications but their use was significantly more frequent in the BPD group. Some data supporting these findings are available in the literature but mainly involve school-age subjects (19-21). A Dutch study investigating the prevalence of cognitive and emotional difficulties in moderately preterm children (gestational age 34 weeks) (21) compared with term-born children showed that prematurity was strongly correlated with cognitive impairments and behavioural problems such as attention deficit hyperactivity disorder. Another study examining preterm infants at five years of age and a control group concluded that preterm infants had more behavioural problems and emotional symptoms (19). No other data - over and above the impact of prematurity itself - regarding the impact of BPD or RDS exist.

\section{Strengths and limitations}

Identification of the subjects relied on medical billing diagnoses (from January 1, 1983 to December 31, 1992) and hospital discharge diagnoses (MED-ECHO) from April 1, 1987 onward. The MED-ECHO databases have been previously validated and found to be reliable (8), but the use of medical billing diagnoses has not. This constitutes a weakness in the selection process, but only spans four years of the total 10 years of subject selection. The free and universal coverage for health care in Quebec is a strength of the present study, especially because prematurity is often observed in a lower socioeconomic stratum, a factor linked to prematurity (22). Because the pharmaceutical database used in the present study is considered to be complete only since January 1, 1997, with all individuals $<18$ years of age benefiting from free and universal coverage for prescription drugs since that time, we have likely underestimated the utilization of medications and associated costs before 1997 and for the earlier years of life of the study population. Similarly, the incompleteness of the medical hospitalization databases from 1983 until April 1, 1987, resulted in an underestimation of the hospitalizations and the associated costs. Another weakness is the extrapolation of the hospitalization costs in the calculation of the health care costs using data from the Canadian Institute of Health Information, which uses the $\mathrm{CMG}+$ methodology (10). The use of the $\mathrm{CMG}+$ methodology does not account for different patterns of care (eg, an individual's response to a particular treatment) or for the inhomogeneity of a patient population. With regard to our study population, not accounting for length of stay outliers would have resulted in an underestimation of the hospitalization costs (23). Although the direct costs of hospitalizations were not tabulated, their values are comparable with what is reported in the literature $(2,24)$.

\section{CONCLUSION}

BPD and RDS are the two most common pulmonary complications that affect preterm infants and contribute to their morbidity and mortality. Improved survival of very premature infants, a consequence of medical advances in neonatal and obstetrical care, has resulted in increased numbers of infants with BPD surviving into adulthood. This increase puts a burden on health resources because these individuals are frequently hospitalized, incur more outpatient and emergency rooms visits, and are more likely to suffer from respiratory illnesses and to use respiratory drugs than RDS subjects. Given these findings, it appears that subjects born prematurely and who suffer from respiratory complications at birth would benefit from being closely followed throughout their late adolescence and early adulthood for the development of late respiratory complications, such as asthma or bronchial hyper-responsiveness attributable to their underlying RDS and BPD. Neurological and psychiatric complications occurred at a high frequency in both RDS and BPD subjects, and were associated with a significant use of antipsychotic and antidepressant medications. The results of the present study are likely generalizable to other Canadians provinces for preterm subjects born during the same period, but the reality of today's preterm infants is likely to be quite different given the evolution of BPD and RDS over the past two decades. The pathogenesis of BPD and RDS has been modulated by the introduction of the routine use of pulmonary surfactants and the more advanced degree of prematurity currently encountered. Further studies addressing the long-term respiratory and mental health consequences of preterm birth are needed to better address the needs and concerns of this growing patient population.

ACKNOWLEDGEMENTS: This study was supported by a grant from the Réseau en Santé Respiratoire - Fonds de la recherche en santé du Québec. 


\section{REFERENCES}

1. White Paper on Preterm Birth, the Global and Regional Toll. White Plains: March of Dimes Foundation, 2009.

2. Petrou S. The economic consequences of preterm birth during the first 10 years of life. Bjog 2005;112(Suppl 1):10-5.

3. International Classification of Diseases, Ninth Revision (ICD-9). Center for Disease Control and Prevention, 2010 <www.cdc.gov/ nchs/icd/icd9.htm> (Accessed February 25, 2010).

4. Landry JS Menzies D. Occurrence and severity of bronchopulmonary dysplasia and respiratory distress syndrome after a preterm birth. Paediatr Child Health 2011;16:399-430.

5. Jobe AH, Bancalari E. Bronchopulmonary dysplasia. Am J Respir Crit Care Med 2001;163:1723-9.

6. Ministère de la Santé et des Services Sociaux du Québec. Cadre Normatif du Système MED-ÉCHO, 2009.

7. Ministère de la Santé et des Services Sociaux du Québec. Les banques de données du MSSS. Numéro 1. Données sur la clientèle hospitalière (MED-ÉCHO). Quebec, 1986.

8. Narang I. Review series: What goes around, comes around: Childhood influences on later lung health? Long-term follow-up of infants with lung disease of prematurity. Chron Respir Dis 2010;7:259-69.

9. Health Canada. The economic burden of illness in Canada, 1998. Ottawa: Health Canada, 2002.

10. Canadian Institute for Health Information, The Cost of Hospital Stays: Why Costs Vary. Ottawa: CIHI, 2008.

11. SAS annotated output: Multinomial logistic regression. <www.ats.ucla.edu/stat/SAS/output/SAS_mlogit.htm> (Accessed May 1, 2009).

12. Armitage P, Berry G, Matthews J. Statistical Methods in Medical Research, 4th edn. Malden: Blackwell Science, 2005.

13. Statistics Canada, Govermment of Canada; Census, 2009. $<$ http://geodepot.statcan.gc.ca/2006/13011619/20080513 0120090313011619_05-eng.jsp> (Accessed September 25, 2009).

14. Gouvernement du Québec. Naissance selon la duree de la grossesse et le poids a la naissance, Quebec, 1975-2007. <www.stat.gouv.qc.ca/donstat/societe/demographie/naisn_deces/ naissance/418.htm $>$ (Accessed October 9, 2009).

15. Jeng SF, Hsu CH, Tsao PN, et al. Bronchopulmonary dysplasia predicts adverse developmental and clinical outcomes in very-lowbirthweight infants. Dev Med Child Neurol 2008;50:51-7.

16. Tapia JL, Agost D, Alegria A, et al. Bronchopulmonary dysplasia: Incidence, risk factors and resource utilization in a population of South American very low birth weight infants. J Pediatr (Rio J). 2006;82:15-20.

17. Landry JS, Chan T, Lands L, Menzies D. Long-term impact of bronchopulmonary dysplasia on pulmonary function. Can Respir J 2011;18:265-70.

18. Renaud J, Berlim MT, Seguin M, McGirr A, Tousignant M, Turecki G. Recent and lifetime utilization of health care services by children and adolescent suicide victims: A case-control study. J Affect Disord 2009;117:168-73.

19. Delobel-Ayoub M, Arnaud C, White-Koning M, et al. Behavioral problems and cognitive performance at 5 years of age after very preterm birth: The EPIPAGE Study. Pediatrics 2009;123:1485-92.

20. Aarnoudse-Moens CS, Weisglas-Kuperus N, van Goudoever JB, Oosterlaan J. Meta-analysis of neurobehavioral outcomes in very preterm and/or very low birth weight children. Pediatrics 2009; 124:717-28.

21. van Baar AL, Vermaas J, Knots E, de Kleine MJ, Soons P. Functioning at school age of moderately preterm children born at 32 to 36 weeks' gestational age. Pediatrics 2009;124:251-7.

22. Kramer MS, Goulet L, Lydon J, et al. Socio-economic disparities in preterm birth: Causal pathways and mechanisms. Paediatr Perinat Epidemiol 2001;15(Suppl 2):104-23.

23. Pink GH, Bolley HB. Physicians in health care management: 3. Case Mix Groups and Resource Intensity Weights: An overview for physicians. 19940419 DCOM-19940419(0820-3946).

24. Mangham LJ, Petrou S, Doyle LW, Draper ES, Marlow N. The cost of preterm birth throughout childhood in England and Wales. Pediatrics 2009;123:e312-27. 


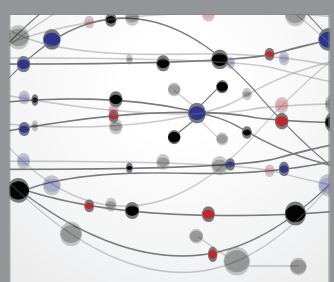

The Scientific World Journal
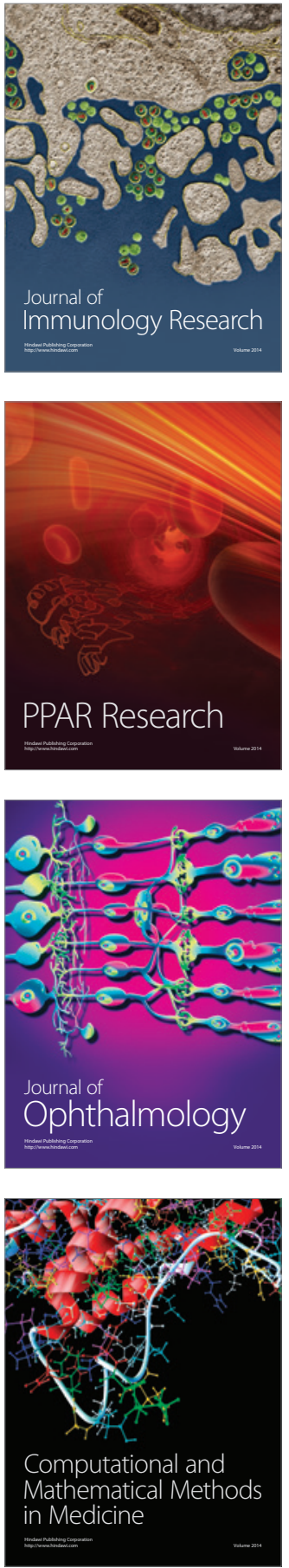

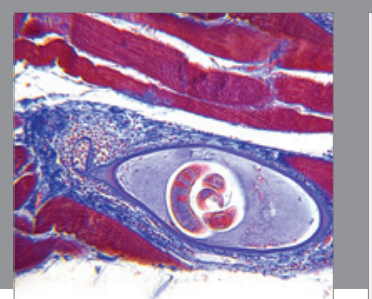

Gastroenterology Research and Practice

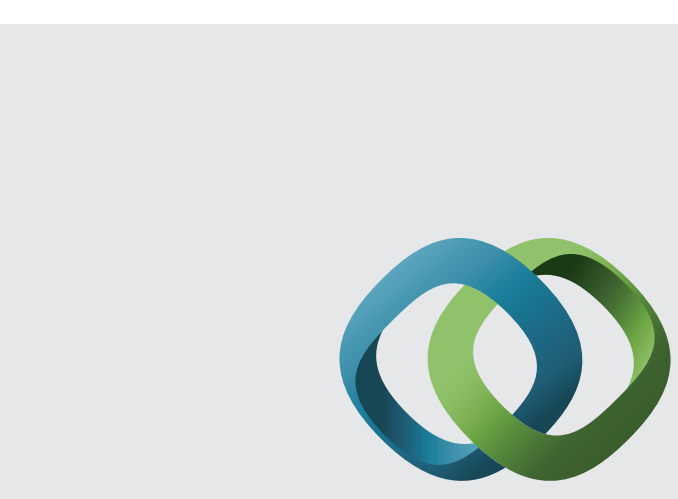

\section{Hindawi}

Submit your manuscripts at

http://www.hindawi.com
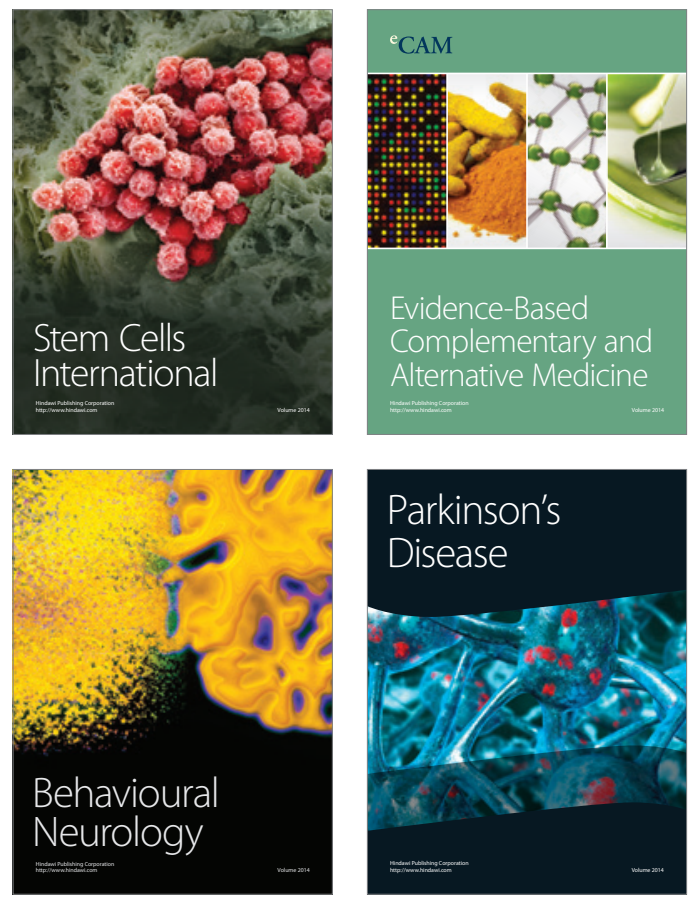
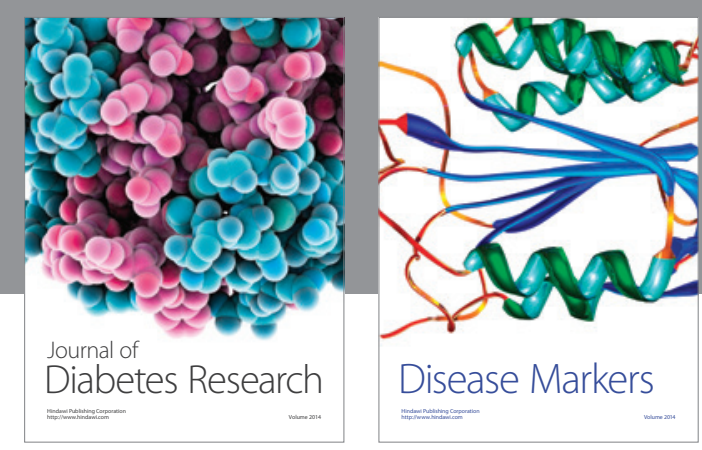

Disease Markers
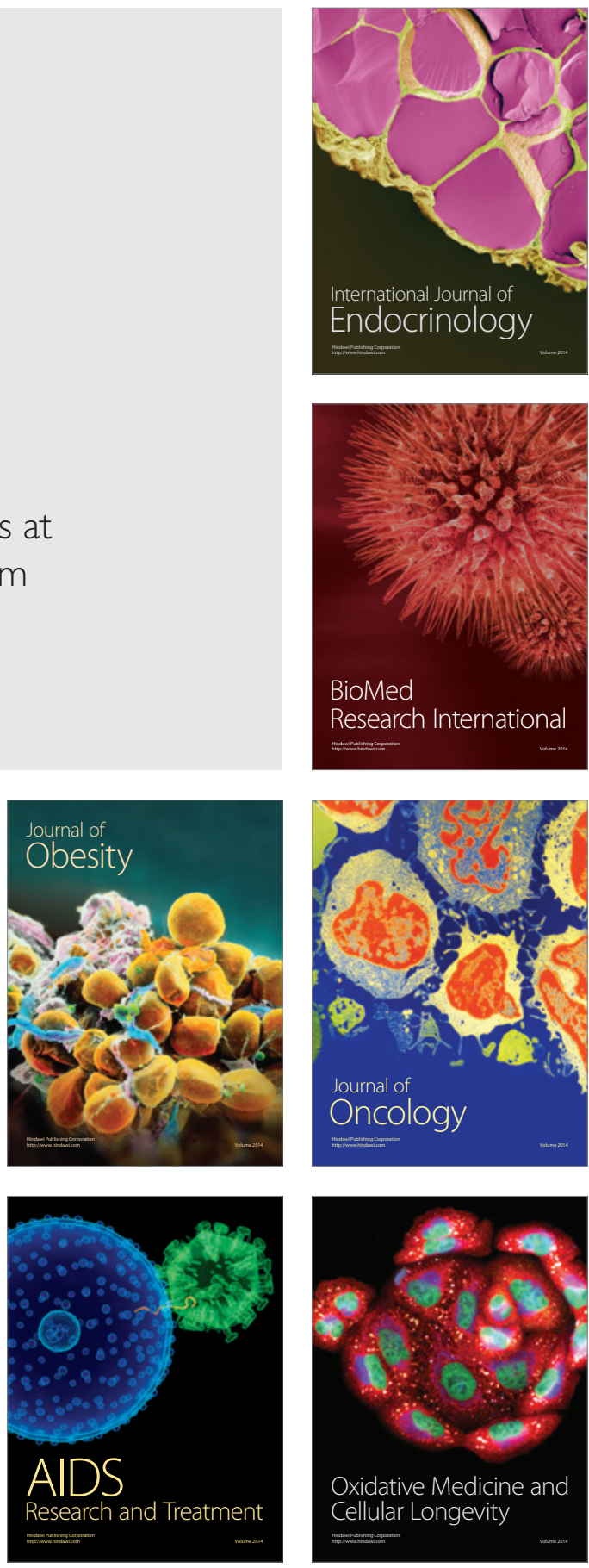